\title{
Article \\ Static Bending and Vibration Analysis of a Rectangular Functionally Gradient Piezoelectric Plate on an Elastic Foundation
}

\author{
Wei Wang ${ }^{1,2}$, Haonan $\mathrm{Li}^{1,3}$ and Linquan Yao ${ }^{1,3, *}$ \\ 1 School of Mathematical Sciences, Soochow University, Suzhou 215006, China; wangw@suda.edu.cn (W.W.); \\ hnli@stu.suda.edu.cn (H.L.) \\ 2 Soochow College, Soochow University, Suzhou 215006, China \\ 3 School of Rail Transportation, Soochow University, Suzhou 215131, China \\ * Correspondence: lqyao@suda.edu.cn
}

check for

updates

Citation: Wang, W.; Li, H.; Yao, L.

Static Bending and Vibration

Analysis of a Rectangular

Functionally Gradient Piezoelectric

Plate on an Elastic Foundation. Appl.

Sci. 2022, 12, 1517. https://doi.org/

10.3390/app12031517

Academic Editors: Ji Wang,

Weiqiu Chen, Bin Huang and

Francesco Tornabene

Received: 3 January 2022

Accepted: 27 January 2022

Published: 30 January 2022

Publisher's Note: MDPI stays neutral with regard to jurisdictional claims in published maps and institutional affiliations.

Copyright: (c) 2022 by the authors. Licensee MDPI, Basel, Switzerland. This article is an open access article distributed under the terms and conditions of the Creative Commons Attribution (CC BY) license (https:/ / creativecommons.org/licenses/by/ $4.0 /)$.

\begin{abstract}
In this paper, a functionally graded piezoelectric plate on an elastic foundation composed of two different piezoelectric materials bonded together in the form of plate is studied, and its static bending and fundamental frequencies are analyzed. First, based on Kirchhoff plate theory and the Hamilton principle, the governing equations and corresponding boundary conditions of the model are derived, and then the equations are discretized and solved by the differential quadrature method (DQM). Finally, the effects of physical parameters such as length-to-height ratio, length-to-width ratio, material graded index, foundation stiffness coefficient, temperature change value and external voltage value on static bending deflection, and fundamental frequency value of the functionally graded piezoelectric plate with four sides simply supported are discussed. The calculated results are in good agreement with those in the literature. The data results show that the increase in the elastic foundation stiffness coefficient will increase the equivalent stiffness of the plate. In the process of work, due to the equivalent pressure value generated by the influence of the external voltage, it will lead to unstable phenomena.
\end{abstract}

Keywords: functionally graded piezoelectric plate; static bending; fundamental frequency value; elastic foundation

\section{Introduction}

Functionally graded materials (FGMs) can reduce or even eliminate the interface between components by continuously controlling the content distribution of each component to meet the different requirements of different parts of structural components for material performance. When piezoelectric materials are subjected to mechanical loading, they generate an electric charge, which is called the positive piezoelectric effect. In contrast, the piezoelectric material will produce mechanical deformation under the electric field effect, which is called the inverse piezoelectric effect. Functionally graded piezoelectric materials (FGPMs) have been developed in recent years to meet the requirements of special conditions and extend the service life. As a new material design concept, FGPMs have very broad application prospects [1-9].

The functional gradient plate structures composed by a variety of materials combine the excellent performance of a variety of component materials, so the functional gradient plates are important in the fields of aerospace, transportation engineering, construction and other fields. The interference of the plate structures is taken from external conditions in the process of work, and many mechanical behaviors such as bending and vibration, so many scholars have made a lot of research on the mechanical behaviors of the plates and have achieved rich research results [10-16]. Mao [17] investigated the modal performance of a sandwich composite plate and provided a new design idea for dynamic behaviors of sandwich plates. Cho [18] et al. introduced FGPMs plates for the modal analysis of ceramic and proposed hierarchic models. Mehrabadi [19] et al. analyzed the free vibration of a 
circular plate composed of FGMs based on classical plate theory. Yao [20] et al. studied vibration behaviors of rotating composite nano-annular plates based on different plate theories and explored the effects of the thickness-to-radius ratio and angular velocity on the natural frequencies. Mlab [21] et al. proposed a new generalized 5-variable shear deformation theory and calculated the static response of FGMs plates. Zenkour [22] et al. studied the bending analysis of a FGPMs plate by using a simple quasi-3D sinusoidal shear deformation theory under simply supported edge conditions.

In the fields of engineering, during the design of the plate structures, it is often placed on an elastic foundation, such as the high-speed shock absorbing layers of the train, which can be considered an elastic foundation. However, an elastic foundation may have an important impact on the mechanical properties of the plates, so many scientific research workers have studied the mechanical behaviors of the plates on an elastic foundation and achieved important research results [23-27].

There are a lot of research results of mechanical behaviors of the FGPMs plates so far but few have studied the mechanical-electrical-thermal coupling of FGPMs. In this paper, the results of a transversely isotropic FGPMs plate under mechanical-electrical-thermal coupling on an elastic foundation are studied, and some references are provided for the design of FGPMs.

\section{Governing Equations}

Considering a rectangular FGPMs plate on an elastic foundation with a length, width and height of $l_{a}, l_{b}, h$, the foundation coefficient is $K$, as shown in Figure 1. In this paper, PZT4 and PZT-5 piezoelectric ceramic materials are applied to constitute a functional gradient composite plate. Since most scholars in past studies have used these two materials when studying the mechanical properties of composite piezoelectric structures, a comparison can be made during the analysis of the data, and the two materials can be used to study the changes of the material gradient index. The resulting conclusions have guided significance for the mechanical properties of the plates formed by other materials. Assume that the materials of a plate are composed of the piezoelectric material PZT - 5 on the lower surface, changing continuously to the material PZT -4 component on the upper surface, and the material properties gradient along the thickness direction, which can be expressed as [28]:

$$
P(z)=P_{5}+\left(P_{4}-P_{5}\right)\left(\frac{1}{2}+\frac{z}{h}\right)^{k}
$$

where $P(z)$ represents physical parameters of the functionally graded material, $P_{4}$ represents physical parameters of the material PZT $-4, P_{5}$ represents physical parameters of the material PZT -5 , and $k$ represents functional graded index.

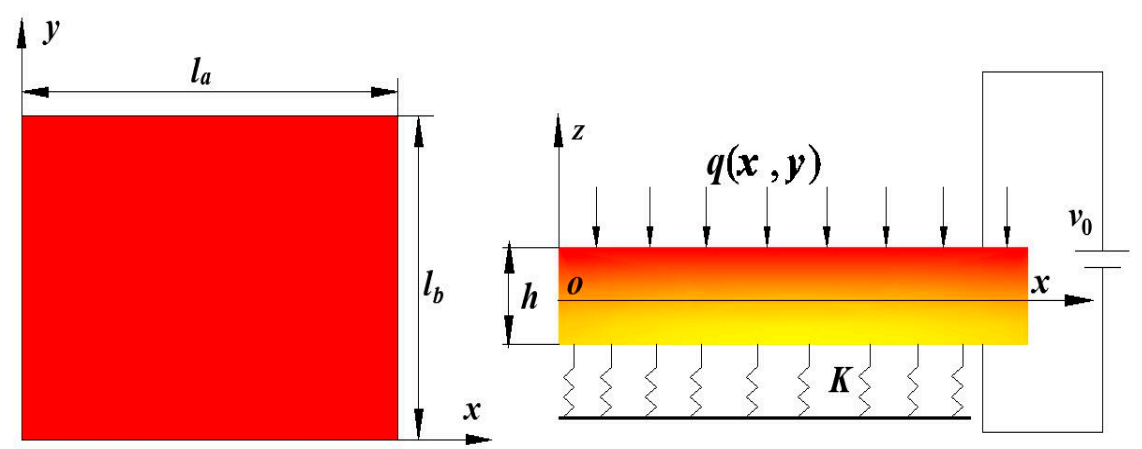

Figure 1. Functionally graded piezoelectric plate on elastic foundation. 
Assuming that the physical middle position $z=z_{0}$ of the FGPMs plate is not coincident with the geometric middle position, it can be obtained according to the literature [29].

$$
z_{0}=\frac{\int_{-h / 2}^{h / 2} z c_{11}(z) \mathrm{d} z}{\int_{-h / 2}^{h / 2} c_{11}(z) \mathrm{d} z}=\frac{\left(c_{11(\mathrm{PZT}-4)}-c_{11(\mathrm{PZT}-5)}\right) k h}{2(2+k)\left(c_{11(\mathrm{PZT}-4)}+k c_{11(\mathrm{PZT}-5)}\right)}
$$

where $c_{11(\mathrm{PZT}-4)}, c_{11(\mathrm{PZT}-5)}$ represent the elastic modulus of the material PZT -4 and the material PZT -5 , respectively.

According to Kirchhoff's plate theory, the displacement of any point in the functionally graded piezoelectric plate can be expressed as

$$
\left\{\begin{array}{l}
u(x, y, z, t)=-\left(z-z_{0}\right) \frac{\partial w}{\partial x} \\
v(x, y, z, t)=-\left(z-z_{0}\right) \frac{\partial w}{\partial y} \\
w(x, y, z, t)=w(x, y, t)
\end{array}\right.
$$

The relationship between the strains and displacement $w$ of the piezoelectric plate can be obtained from geometric relations

$$
\left\{\begin{array}{l}
\varepsilon_{x x}=-\left(z-z_{0}\right) \frac{\partial^{2} w}{\partial x^{2}} \\
\varepsilon_{y y}=-\left(z-z_{0}\right) \frac{\partial^{2} w}{\partial x^{2}} \\
\varepsilon_{x y}=-\left(z-z_{0}\right) \frac{\partial^{2} w}{\partial x \partial y}
\end{array}\right.
$$

For the Kirchhoff functionally graded piezoelectric plate model, the constitutive relations under mechanical-electro-thermal coupling can be expressed as

$$
\begin{aligned}
& \left\{\begin{array}{l}
\sigma_{x x} \\
\sigma_{y y} \\
\sigma_{x y}
\end{array}\right\}=\left[\begin{array}{ccc}
C_{11} & C_{12} & 0 \\
C_{12} & C_{11} & 0 \\
0 & 0 & C_{66}
\end{array}\right]\left\{\begin{array}{c}
\varepsilon_{x x} \\
\varepsilon_{y y} \\
2 \varepsilon_{x y}
\end{array}\right\}-\left[\begin{array}{ccc}
0 & 0 & e_{31} \\
0 & 0 & e_{31} \\
0 & 0 & 0
\end{array}\right]\left\{\begin{array}{l}
E_{x} \\
E_{y} \\
E_{z}
\end{array}\right\}-\left\{\begin{array}{l}
\beta_{1} \\
\beta_{1} \\
0
\end{array}\right\} \Delta T \\
& \left\{\begin{array}{l}
D_{x} \\
D_{y} \\
D_{z}
\end{array}\right\}=\left[\begin{array}{ccc}
0 & 0 & 0 \\
0 & 0 & 0 \\
e_{31} & e_{31} & 0
\end{array}\right]\left\{\begin{array}{c}
\varepsilon_{x x} \\
\varepsilon_{y y} \\
2 \varepsilon_{x y}
\end{array}\right\}+\left[\begin{array}{ccc}
s_{11} & 0 & 0 \\
0 & s_{11} & 0 \\
0 & 0 & s_{33}
\end{array}\right]\left\{\begin{array}{l}
E_{x} \\
E_{y} \\
E_{z}
\end{array}\right\}+\left\{\begin{array}{c}
0 \\
0 \\
a_{3}
\end{array}\right\} \Delta T
\end{aligned}
$$

In the expression, $\sigma_{x x}$ and $\sigma_{y y}$ are $x$ directional normal stress and $y$ directional normal stress, respectively; $\sigma_{x y}$ is in-plane shear stress; $\varepsilon_{x x}, \varepsilon_{y y}$ are $x$ directional and $y$ directional normal strains, respectively; $\varepsilon_{x y}$ is in-plane shear strain; $D_{x}, D_{y}$ and $D_{z}$ are electric displacements in three directions of $x, y, z ; E_{x}, E_{y}$ and $E_{z}$ are the electric field intensity in the three directions of $x, y, z$, respectively; $C_{11}, C_{12}$ and $C_{66}$ are the elastic moduli; $e_{31}$ is piezoelectric coefficient; $S_{11}$ and $S_{33}$ are dielectric coefficients; $\beta_{1}, a_{3}$ and $\Delta T$ are the thermo-elastic modulus, pyroelectric constant and temperature change value, respectively.

As shown in Figure 1, the static voltage is applied along the thickness of the plate, and without considering the physical force and free charge, the equilibrium equation of the electric displacement can be expressed as

$$
\frac{\partial D_{z}}{\partial z}=0
$$

Let the electric potential at any point in the direction of plate thickness be $\phi(x, y, z, t)$, which can be written from the relationship between electric potential and electric field intensity as

$$
E_{\mathrm{z}}=-\frac{\partial \phi}{\partial z}
$$


According to expressions (6)-(8) and boundary conditions $\phi(h / 2)=v_{0}$ and $\phi(-h / 2)=0$, the expressions of electric potential and electric field intensity can be written as

$$
\begin{gathered}
\phi=\frac{e_{31}}{s_{33}}\left(\frac{z^{2}}{2}-\frac{h^{2}}{8}\right)\left(\frac{\partial^{2} w}{\partial x^{2}}+\frac{\partial^{2} w}{\partial y^{2}}\right)+\frac{v_{0}}{h} z+\frac{v_{0}}{2} \\
E_{z}=-\frac{e_{31} z}{s_{33}}\left(\frac{\partial^{2} w}{\partial x^{2}}+\frac{\partial^{2} w}{\partial y^{2}}\right)-\frac{v_{0}}{h}
\end{gathered}
$$

the strain energy density per unit volume of the rectangular plate is

$$
U=\frac{1}{2}\left(\sigma_{x x} \varepsilon_{x x}+\sigma_{y y} \varepsilon_{y y}+\sigma_{x y} \varepsilon_{x y}-D_{x} E_{x}-D_{z} E_{z}\right),
$$

the kinetic energy of the rectangular plate is

$$
T=\frac{1}{2} \int_{\Omega} \rho\left(\dot{u}^{2}+\dot{v}^{2}+\dot{w}^{2}\right) \mathrm{d} \Omega,
$$

and the external potential energy of the rectangular plate is

$$
W_{F}=-\iint q w \mathrm{~d} x \mathrm{~d} y+\frac{1}{2} \iint\left\{N_{x}\left(\frac{\partial w}{\partial x}\right)^{2}+N_{y}\left(\frac{\partial w}{\partial y}\right)^{2}+2 N_{x y}\left(\frac{\partial w}{\partial x} \frac{\partial w}{\partial y}\right)+K w^{2}\right\} \mathrm{d} x \mathrm{~d} y
$$

where $q$ is the uniform load imposed on the surface of the rectangular plate. The axial force $N_{x}$ and $N_{y}$ of the $x$ and $y$ directions can be expressed as

$$
\left\{\begin{array}{l}
N_{x}=N_{E x}+N_{T x} \\
N_{y}=N_{E y}+N_{T y}
\end{array} .\right.
$$

$\left(N_{E x}, N_{E y}\right)$ are the axial force generated in the directions $x$ and $y$ under the action of external static voltage; $\left(N_{T x}, N_{T y}\right)$ are the axial force generated by the temperature change in the $x$ and $y$ directions.

$$
N_{E x}=N_{E y}=-\int_{-h / 2}^{h / 2} e_{31} v_{0} \mathrm{~d} z, N_{T x}=N_{T y}=\beta_{1} h \Delta T
$$

According to Hamilton principle, the variation in the total energy is divided into zero, i.e.,

$$
\delta \int_{0}^{t}\left(\iiint_{\Omega} U \mathrm{~d} \Omega+W_{F}-T\right) \mathrm{d} t=0
$$

Substituting Equations (11)-(13) into Equation (16), the governing equation of the rectangular plate is

$$
\begin{aligned}
& \frac{\partial^{2} M_{x x}}{\partial x^{2}}+\frac{\partial^{2} M_{y y}}{\partial y^{2}}+2 \frac{\partial^{2} M_{x y}}{\partial x \partial y}-E_{31}^{2} \frac{\partial^{4} w}{\partial x^{4}}-2 E_{31}^{2} \frac{\partial^{4} w}{\partial x^{2} \partial y^{2}}-E_{31}^{2} \frac{\partial^{4} w}{\partial y^{4}}+N_{x} \frac{\partial^{2} w}{\partial x^{2}}+N_{y} \frac{\partial^{2} w}{\partial y^{2}}-k w-q \\
& =-I_{0} \frac{\partial^{2} w}{\partial t^{2}}+I_{2} \frac{\partial^{4} w}{\partial x^{2} \partial t^{2}}+I_{2} \frac{\partial^{4} w}{\partial y^{2} \partial t^{2}}
\end{aligned}
$$

and the simply supported boundary condition of the plate is deduced as follows:

$$
\begin{cases}x=0, l_{a} & \frac{\partial^{2} w}{\partial x^{2}}=0 \\ y=0, l_{b} & \frac{\partial^{2} w}{\partial y^{2}}=0\end{cases}
$$


The bending moments $M_{x x}$ and $M_{y y}$, and the expression of torque $M_{x y}$ in the governing Equation (17) are defined as

$$
\left\{\begin{array}{l}
M_{x x} \\
M_{y y} \\
M_{x y}
\end{array}\right\}=\int_{-h / 2}^{h / 2}\left(z-z_{0}\right)\left\{\begin{array}{l}
\sigma_{x x} \\
\sigma_{y y} \\
\sigma_{x y}
\end{array}\right\} \mathrm{d} z
$$

The expressions of the bending moments and the torque can be derived from matrix Equation (5):

$$
\left\{\begin{array}{l}
M_{x x} \\
M_{y y} \\
M_{x y}
\end{array}\right\}=\left[\begin{array}{ccc}
\left(-D_{11}+E_{31}^{1}\right) & \left(-D_{12}+E_{31}^{1}\right) & 0 \\
\left(-D_{12}+E_{31}^{1}\right) & \left(-D_{11}+E_{31}^{1}\right) & 0 \\
0 & 0 & -2 D_{66}
\end{array}\right]\left\{\begin{array}{l}
\frac{\partial^{2} w}{\partial x^{2}} \\
\frac{\partial^{2} w}{\partial y^{2}} \\
\frac{\partial^{2} w}{\partial x \partial y}
\end{array}\right\}+\left\{\begin{array}{c}
M_{e}-M_{T} \\
M_{e}-M_{T} \\
0
\end{array}\right\}
$$

Substituting Equation (20) into Equation (17) to obtain an expression with displacement $w$ as a variable:

$$
\begin{aligned}
& \left(-D_{11}+E_{31}^{1}-E_{31}^{2}\right) \frac{\partial^{4} w}{\partial x^{4}}+\left(-D_{11}+E_{31}^{1}-E_{31}^{2}\right) \frac{\partial^{4} w}{\partial y^{4}}+\left(-2 D_{12}+2 E_{31}^{1}-2 E_{31}^{2}-4 D_{66}\right) \frac{\partial^{4} w}{\partial x^{2} \partial y^{2}}+N_{x} \frac{\partial^{2} w}{\partial x^{2}}+N_{y} \frac{\partial^{2} w}{\partial y^{2}} \\
& -k w-q=-I_{0} \frac{\partial^{2} w}{\partial t^{2}}+I_{2} \frac{\partial^{4} w}{\partial x^{2} \partial t^{2}}+I_{2} \frac{\partial^{4} w}{\partial y^{2} \partial t^{2}}
\end{aligned}
$$

The correlation coefficients in Equations (20) and (21) are expressed as

$$
\left\{\begin{array}{l}
D_{11}=\int_{-h / 2}^{h / 2} C_{11}\left(z-z_{0}\right)^{2} \mathrm{~d} z \quad D_{12}=\int_{-h / 2}^{h / 2} C_{12}\left(z-z_{0}\right)^{2} \mathrm{~d} z \\
D_{66}=\int_{-h / 2}^{h / 2} C_{66}\left(z-z_{0}\right)^{2} \mathrm{~d} z \quad E_{31}^{1}=\int_{-h / 2}^{h / 2} \frac{e_{31}^{2}}{s_{33}} z\left(z-z_{0}\right) \mathrm{d} z \\
E_{31}^{2}=\int_{-h / 2}^{h / 2} \frac{e_{31}^{2}}{s_{33}} z\left(2 z-z_{0}\right) \mathrm{d} z \quad M_{e}=\int_{-h / 2}^{h / 2} e_{31}\left(z-z_{0}\right) \frac{v_{0}}{h} \mathrm{~d} z \\
M_{T}=\int_{-h / 2}^{h / 2} \beta_{1} \Delta T\left(z-z_{0}\right) \mathrm{d} z \quad I_{0}=\int_{A} \rho(z) \cdot\left(z-z_{0}\right) \mathrm{d} A \\
I_{2}=\int_{A} \rho(z) \cdot\left(z-z_{0}\right)^{2} \mathrm{~d} z
\end{array}\right.
$$

From Equation (21), we can obtain the free vibration Equation (23) and the static bending Equation (24) of the rectangular plate, respectively:

$$
\begin{aligned}
& \left(-D_{11}+E_{31}^{1}-E_{31}^{2} \frac{\partial^{4} w}{\partial x^{4}}+\left(-D_{11}+E_{31}^{1}-E_{31}^{2} \frac{\partial^{4} w}{\partial y^{4}}+\left(-2 D_{12}+2 E_{31}^{1}-2 E_{31}^{2}-4 D_{66}\right) \frac{\partial^{4} w}{\partial x^{2} \partial y^{2}}+N_{x} \frac{\partial^{2} w}{\partial x^{2}}+N_{y} \frac{\partial^{2} w}{\partial y^{2}}\right.\right. \\
& -k w=-I_{0} \frac{\partial^{2} w}{\partial t^{2}}+I_{2} \frac{\partial^{4} w}{\partial x^{2} \partial t^{2}}+I_{2} \frac{\partial^{4} w}{\partial y^{2} \partial t^{2}} \\
& \left(-D_{11}+E_{31}^{1}-E_{31}^{2}\right) \frac{\partial^{4} w}{\partial x^{4}}+\left(-D_{11}+E_{31}^{1}-E_{31}^{2}\right) \frac{\partial^{4} w}{\partial y^{4}}+\left(-2 D_{12}+2 E_{31}^{1}-2 E_{31}^{2}-4 D_{66}\right) \frac{\partial^{4} w}{\partial x^{2} \partial y^{2}}+N_{x} \frac{\partial^{2} w}{\partial x^{2}}+N_{y} \frac{\partial^{2} w}{\partial y^{2}}-k w=q
\end{aligned}
$$

When the piezoelectric rectangular plate vibrates linearly, its displacement can be expressed in the form of space-time separation:

$$
w=\widetilde{w} e^{i \omega t}
$$

Therefore, the free vibration Equation (23) can be further represented as

$$
\begin{aligned}
& \left(-D_{11}+E_{31}^{1}-E_{31}^{2}\right) \frac{\partial^{4} \widetilde{w}}{\partial x^{4}}+\left(-D_{11}+E_{31}^{1}-E_{31}^{2}\right) \frac{\partial^{4} \widetilde{w}}{\partial y^{4}}+\left(-2 D_{12}+2 E_{31}^{1}-2 E_{31}^{2}-4 D_{66}\right) \frac{\partial^{4} \widetilde{w}}{\partial x^{2} \partial y^{2}}+N_{x} \frac{\partial^{2} \widetilde{w}}{\partial x^{2}}+N_{y} \frac{\partial^{2} \widetilde{w}}{\partial y^{2}} \\
& -k \widetilde{w}=\omega^{2}\left(I_{0} \widetilde{w}-I_{2} \frac{\partial^{2} \widetilde{w}}{\partial x^{2}}-I_{2} \frac{\partial^{2} \widetilde{w}}{\partial y^{2}}\right)
\end{aligned}
$$

The DQM is adopted in this paper to discretize the differential Equations (24) and (26) to algebraic equations. Then, to solve the obtained algebraic equations, the eigenvalue 
process will be applied. According to the idea of the DQM [29], the $r$-th derivative order of function $f(x)$ can be expressed as

$$
\left.\frac{\partial^{r} f(x)}{\partial x^{r}}\right|_{x=x_{i}}=\sum_{j=1}^{n} c_{i j}^{r} f\left(x_{i}\right)
$$

where $n$ is the number of grid points along $x$ direction and $c_{i j}^{r}$ can be expressed as

$$
\left\{\begin{array}{l}
c_{i j}^{r}=r\left[c_{i i}^{r-1} c_{i j}^{1}-\frac{c_{i j}^{r-1}}{\left(x_{i}-x_{j}\right)}\right] \quad(i, j=1,2, \ldots, n, \quad i \neq j \text { and } 2 \leq r \leq n-1) \\
c_{i j}^{1}=\frac{M\left(x_{i}\right)}{\left(x_{i}-x_{j}\right) M\left(x_{j}\right)}(i, j=1,2, \ldots, n, \quad i \neq j) \\
c_{i i}^{r}=-\sum_{j=1, i \neq j}^{n} c_{i j}^{r}(i=1,2, \ldots, n, \quad r=1,2, \ldots, n-1) \\
M\left(x_{i}\right)=\prod_{j=1, i \neq j}^{n}\left(x_{i}-x_{j}\right) \quad(i=1,2, \ldots, n)
\end{array}\right.
$$

According to the method of picking points, the characteristic points of $N_{1}$ and $N_{2}$ are placed discretely along the $X$-axis and $Y$-axis, respectively, in the domain of a functionally graded piezoelectric plate, and the coordinates of the discrete points are

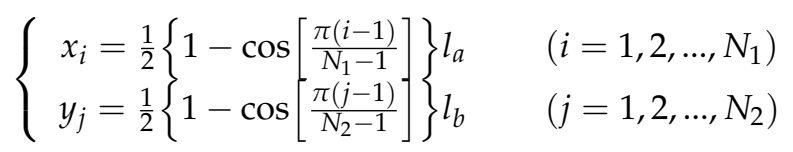

Then, the discrete equations of free vibration and static bending of piezoelectric plates are obtained

$$
\begin{aligned}
& \left(-D_{11}+E_{31}^{1}-E_{31}^{2}\right) \sum_{m=1}^{N_{1}} \sum_{n=1}^{N_{2}} c_{i m}^{4} c_{j n}^{0} \widetilde{w}_{m n}+N_{x} \sum_{m=1}^{N_{1}} \sum_{n=1}^{N_{2}} c_{i m}^{2} c_{j n}^{0} \widetilde{w}_{m n}+\left(-D_{11}+E_{31}^{1}-E_{31}^{2}\right) \sum_{m=1}^{N_{1}} \sum_{n=1}^{N_{2}} c_{i m}^{0} c_{j n}^{4} \widetilde{w}_{m n}+N_{y} \sum_{m=1}^{N_{1}} \sum_{n=1}^{N_{2}} c_{i m}^{0} c_{j n}^{2} \widetilde{w}_{m n} \\
& +\left(-2 D_{12}+2 E_{31}^{1}-2 E_{31}^{2}-4 D_{66}\right) \sum_{j=1}^{n} c_{i m}^{2} c_{j n}^{2} \widetilde{w}_{m n}-K \widetilde{w}_{m n}=\omega^{2}\left(m_{0} \widetilde{w}_{m n}-m_{2} \sum_{m=1}^{N_{1}} \sum_{n=1}^{N_{2}} c_{i m}^{2} c_{j n}^{0} \widetilde{w}_{m n}-m_{2} \sum_{m=1}^{N_{1}} \sum_{n=1}^{N_{2}} c_{i m}^{0} c_{j n}^{2} \widetilde{w}_{m n}\right) \\
& \left(-D_{11}+E_{31}^{1}-E_{31}^{2}\right) \sum_{m=1}^{N_{1}} \sum_{n=1}^{N_{2}} c_{i m}^{4} c_{j n}^{0} w_{m n}+N_{x} \sum_{m=1}^{N_{1}} \sum_{n=1}^{N_{2}} c_{i m}^{2} c_{j n}^{0} w_{m n}+\left(-D_{11}+E_{31}^{1}-E_{31}^{2}\right) \sum_{m=1}^{N_{1}} \sum_{n=1}^{N_{2}} c_{i m}^{0} c_{j n}^{4} w_{m n}+N_{y} \sum_{m=1}^{N_{1}} \sum_{n=1}^{N_{2}} c_{i m}^{0} c_{j n}^{2} w_{m n} \\
& +\left(-2 D_{12}+2 E_{31}^{1}-2 E_{31}^{2}-4 D_{66}\right) \sum_{j=1}^{n} c_{i m}^{2} c_{j n}^{2} w_{m n}-K w_{m n}=q
\end{aligned}
$$

\section{Calculation Results and Analysis}

To facilitate data processing, each quantity is made dimensionless first

$$
\left\{\begin{array}{l}
\bar{w}=\frac{w}{h}, \overline{\widetilde{w}}=\frac{\widetilde{w}}{h}, \bar{x}=\frac{x}{l_{a}}, \bar{y}=\frac{y}{l_{b}}, \lambda=\frac{l_{a}}{l_{b}}, \eta=\frac{l_{a}}{h}, \\
\tau=\frac{t}{l_{a}} \sqrt{\frac{A_{10}}{I_{10}}}, \bar{\omega}=\omega l_{a} \sqrt{\frac{I_{10}}{A_{10}}}, \bar{q}=\frac{q l_{a}^{4}}{A_{10} h^{3}}, \\
\bar{K}=\frac{K l_{a}^{4}}{A_{10} h^{2}}, A_{10}=h C_{11(\text { PZT }-4)}, I_{10}=h \rho_{(\text {PZT }-4)}
\end{array}\right.
$$

To verify the validity of the model and the accuracy of the calculation, the static bending problem of a piezoelectric thin plate made of a single material was first calculated by referring to the relevant data in the literature [30], and the results were compared with those in the literature [30]. According to the data in Table 1, the numerical results in this paper are in good agreement with those in the literature. Therefore, the validity of the model and the accuracy of the calculation can be verified. 
Table 1. Comparison of deflection values at the centers of the plates.

\begin{tabular}{ccccc}
\hline & & $\boldsymbol{l}_{\boldsymbol{a}}=\boldsymbol{l}_{\boldsymbol{b}}=30 \boldsymbol{h}$ & $\begin{array}{l}\boldsymbol{l}_{\boldsymbol{a}}=30 \boldsymbol{h} \\
\boldsymbol{l}_{\boldsymbol{b}}=50 \boldsymbol{h}\end{array}$ & $\boldsymbol{l}_{\boldsymbol{a}}=\boldsymbol{l}_{\boldsymbol{b}}=50 \boldsymbol{h}$ \\
\hline \multirow{2}{*}{$h=30 \mathrm{~nm}$} & This paper & 0.3123 & 0.6565 & 0.8203 \\
& literature [30] & 0.3123 & 0.6565 & 0.8203 \\
\hline \multirow{2}{*}{$h=100 \mathrm{~nm}$} & This paper & 0.8571 & 1.6502 & 8.2253 \\
& literature [30] & 0.8571 & 1.6502 & 8.2253 \\
\hline
\end{tabular}

Then, based on Kirchhoff's plate theory, the static bending and free vibration behaviors of the four-sided simply supported FGPMs plate are analyzed, and the effects of the functional graded index, length-to-width ratio, length-to-height ratio, foundation stiffness coefficient, temperature change value and external voltage value on the static bending deflection, and fundamental frequency value are discussed. The related physical parameters of the FGMs are shown in Table 2.

Table 2. Physical parameter values at room temperature.

\begin{tabular}{cccc}
\hline & Properties & PZT-4 & PZT-5 \\
\hline Elastic constant & $C_{11}$ & 81.3 & 60.6 \\
$(\mathrm{GPa})$ & $\mathrm{C}_{12}$ & 25.6 & 23.0 \\
Piezoelectric constant & $\mathrm{C}_{66}$ & 30.5 & 35.5 \\
$\left(\mathrm{C} / \mathrm{m}^{2}\right)$ & $e_{31}$ & -4.1 & -17.05 \\
Dielectric constant & $S_{33}$ & $10.27 \times 10^{-9}$ & $25.54 \times 10^{-9}$ \\
$(\mathrm{C} / \mathrm{Vm})$ & $\beta_{1}$ & $4.738 \times 10^{5}$ & $4.738 \times 10^{5}$ \\
$\begin{array}{c}\text { Thermoelastic modulus } \\
\left(\mathrm{N} / \mathrm{m}^{-2} \mathrm{~K}^{-1}\right)\end{array}$ & $a_{3}$ & $2.5 \times 10^{-5}$ & $2.5 \times 10^{-5}$ \\
Pyroelectric constant & & 7500 & 7500 \\
$\left(\mathrm{C} / \mathrm{m}^{-2} \mathrm{~K}^{-1}\right)$ & $\rho$ & &
\end{tabular}

Table 3 shows that the larger the foundation stiffness coefficient is, the smaller the center deflection value is and the larger the fundamental frequency value is. Through changes in data, we can analyze that the increase in elastic coefficient can enhance the equivalent stiffness of the plate, increase the ability of the plate to resist the deformation, improve the fundamental frequency value of the plate and increase the stability of its operation.

Table 3. Fundamental frequency values and center point deflection values of the plate under different foundation stiffness coefficients $\bar{K}\left(k=0, V_{0}=0, \Delta T=0, \lambda=1, \eta=30, \bar{q}=1\right)$.

\begin{tabular}{ccc}
\hline $\bar{K}$ & $\bar{w}(\bar{x}=\bar{y}=0.5)$ & $\bar{\omega}_{1}$ \\
\hline 0 & 0.0478 & 0.1915 \\
10 & 0.0365 & 0.2185 \\
30 & 0.0246 & 0.2645 \\
50 & 0.0184 & 0.3035 \\
100 & 0.0112 & 0.3841 \\
\hline
\end{tabular}

Table 4 shows that under the same length-to-width ratio, the changes of the gradient index have little influence on the deflection value of the central point. Under the same functional gradient index, the larger the length-to-width ratio is, the smaller the deflection value of the center point is. The increase in the length-to-width ratio increases the equivalent stiffness of the plate to increase its ability to resist deformation. The equivalent stiffness of the plate is not large when the functional gradient index value changes, and therefore, when designing a FGPMs plate, the selection of material components can be flexible. 
Table 4. Deflection values of central point of the plate with different gradient indexes $k$ and length-towidth ratios $\lambda\left(V_{0}=0, \Delta T=0, \eta=30, \bar{K}=50, \bar{q}=1\right)$.

\begin{tabular}{cccccc}
\hline \multicolumn{5}{c}{$k$} \\
\hline$\lambda$ & PZT-4 $(k=0)$ & $\mathbf{1}$ & $\mathbf{2}$ & $\mathbf{3}$ & PZT-5 $(\boldsymbol{k}=\boldsymbol{\infty})$ \\
\hline 1 & 0.0184 & 0.0189 & 0.0195 & 0.0164 & 0.0193 \\
2 & 0.0059 & 0.0063 & 0.0068 & 0.0047 & 0.0066 \\
3 & 0.0017 & 0.0018 & 0.0020 & 0.0013 & 0.0019 \\
4 & $5.771 \times 10^{-4}$ & $6.162 \times 10^{-4}$ & $6.782 \times 10^{-4}$ & $4.326 \times 10^{-4}$ & $6.523 \times 10^{-4}$ \\
\hline
\end{tabular}

Table 5 shows that under the same voltage, the greater the temperature change value is, the greater the fundamental frequency value is. When the temperature change value is small (for example, when $\Delta T=0$ ), the larger the voltage difference is, the larger the fundamental frequency value will be. When the temperature change value increases to a certain extent (e.g., when $\Delta T \geq 100$ ), as the voltage value gradually increases, the fundamental frequency will gradually increase, but the changes in the trend are not obvious. This shows that when the temperature change value is low, the changes of the voltage value have great impacts on the fundamental frequency value, and the greater the voltage is, the greater the fundamental frequency value is. When the temperature change is too high, the changes of voltage value have little effects on the fundamental frequency value.

Table 5. Fundamental frequency values of vibration under different voltage values $V$ and temperature change values $\Delta T(k=1, \eta=30, \lambda=1, \bar{K}=50, \bar{q}=0)$.

\begin{tabular}{ccccc}
\hline \multicolumn{5}{c}{$\Delta \boldsymbol{T}(\mathbf{K})$} \\
\hline $\boldsymbol{V ( \mathbf { v } )}$ & $\mathbf{0}$ & $\mathbf{1 0 0}$ & $\mathbf{3 0 0}$ & $\mathbf{5 0 0}$ \\
\hline-0.4 & 0 & 8.221 & 14.28 & 18.44 \\
0 & 0.2996 & 8.259 & 14.30 & 18.46 \\
0.2 & 0.6367 & 8.278 & 14.31 & 18.47 \\
0.4 & 0.8492 & 8.297 & 14.32 & 18.48 \\
\hline
\end{tabular}

Table 6 shows that under the same length-to-width ratio, the greater the length-toheight ratio is, the greater the deflection value of the center point is. Under the same length-to-height ratio, the larger the length-to-width ratio is, the smaller the deflection value of the center point is. As can be seen from the table data, the changes of the variation of the two types of geometric parameters are opposite to the mechanical performance of the plate. The increase in the length-to-height ratio will increase the flexibility of the plate, making it easier to become deformed. The growth of the length-to-width ratio can increase the ability to resist deformation. Therefore, while combining engineering when designing a FGPMs plate, it is necessary to consider these two geometric parameters, so that the mechanical performance of the plate achieved is optimal.

Table 6. Deflection values of the center point of the plate with different length-to-height ratios $\eta$ and length-to-width ratios $\lambda(k=1, \bar{K}=50, V=0.2, \Delta T=100 \mathrm{~K}, \bar{q}=1)$.

\begin{tabular}{ccccc}
\hline \multicolumn{5}{c}{$\lambda$} \\
\hline $\boldsymbol{\eta}$ & $\mathbf{1}$ & $\mathbf{2}$ & $\mathbf{3}$ & $\mathbf{4}$ \\
\hline 10 & $1.324 \times 10^{-5}$ & $5.117 \times 10^{-6}$ & $2.448 \times 10^{-6}$ & $1.396 \times 10^{-6}$ \\
20 & $2.353 \times 10^{-5}$ & $9.091 \times 10^{-6}$ & $4.348 \times 10^{-6}$ & $2.478 \times 10^{-6}$ \\
30 & $5.287 \times 10^{-5}$ & $2.043 \times 10^{-5}$ & $9.760 \times 10^{-6}$ & $5.553 \times 10^{-6}$ \\
40 & $2.098 \times 10^{-4}$ & $8.103 \times 10^{-5}$ & $3.852 \times 10^{-5}$ & $2.172 \times 10^{-5}$ \\
\hline
\end{tabular}

\section{Conclusions}

In this paper, a FGPMs plate on an elastic foundation composed of two different piezoelectric materials bonded together in the form of plate is studied, and we explore the 
influence of various physical parameters on the static bending and fundamental frequency value of the plate. However, in the process of research, we only consider the linear mechanics behaviors of the plate, and so we will study the contents of nonlinear mechanical behaviors in the next work.

It is concluded that under the same additional conditions: (1) Due to the effect of piezoelectric coefficients, the negative voltage value causes pressure in the middle to press the cross section of the plate, so that the voltage value in the process of operation avoids too much, otherwise it will result in an unstable phenomenon. (2) The larger the foundation stiffness coefficient is, the larger the equivalent stiffness of the plate is, the smaller the deflection is and the larger the fundamental frequency value is. An increase in the elastic foundation coefficient will increase the equivalent stiffness of the plate. (3) The larger the length-to-width ratio is, the larger the equivalent stiffness is, the smaller the deflection is and the larger the fundamental frequency value is. The larger the length-to-height ratio is, the smaller the equivalent stiffness. The length-to-width ratio and length-to-height ratio of two different geometric parameters have different effects on the equivalent stiffness of the plate, so appropriate values should be selected, allowing the mechanical properties of the plate to achieve the best, so that it is stable. (4) The FGPMs plate composed of the two materials of PZT-4 and PZT-5, when the material component changes, the changes on the equivalent stiffness of the plate are not large, which is because the physical properties and electrical properties of the two materials are relatively close.

Author Contributions: Conceptualization, W.W., H.L. and L.Y.; methodology, W.W., H.L. and L.Y.; software, W.W. and H.L.; validation, W.W., H.L. and L.Y.; formal analysis, W.W. and H.L.; investigation, W.W. and H.L.; resources, W.W. and H.L.; data curation, W.W., H.L. and L.Y.; writing-original draft preparation, W.W.; writing-review and editing, W.W.; visualization, W.W. and H.L.; supervision, L.Y. and W.W.; project administration, L.Y.; funding acquisition, L.Y. All authors have read and agreed to the published version of the manuscript.

Funding: This work was funded by the National Natural Science Foundation of China (Grant Nos. 11572210).

Institutional Review Board Statement: Not applicable.

Informed Consent Statement: Not applicable.

Data Availability Statement: Not applicable.

Acknowledgments: This work was supported by the National Natural Science Foundation of China (Grant Nos. 11572210).

Conflicts of Interest: The authors declare no conflict of interest.

\section{References}

1. Rabin, B.H.; Shiota, I. Functionally gradient materials. J. MRS Bull. 1995, 20, 14-18. [CrossRef]

2. Wu, C.C.M.; Kahn, M.; Moy, W. Piezoelectric ceramics with functional gradients: A new Application in Material design. J. Am. Ceram. Soc. 1996, 79, 809-812. [CrossRef]

3. Zhu, X.H.; Meng, Z.Y. Operational principle, fabrication and displacement characteristics of a functionally gradient piezoelectric ceramic actuator. J. Sens. Actuators A 1995, 48, 169-173. [CrossRef]

4. Fan, G.F.; Tang, Y.Q.; Lu, W.Z. Reduce synthesis temperature and improve dispersion of YAG nanopowders based on the co-crystallization method. J. Alloy. Comped. 2015, 618, 1-6. [CrossRef]

5. Su, X.; Zhou, J.; Bai, G. Low temperature synthesis and characterization of YAG nanopowders by polyacrylamide gel method. Ceram. Int. 2016, 42, 17497-17502. [CrossRef]

6. Wu, D.; Cheng, Y.; Feng, S.; Yao, Z.; Zhang, M. Crystallization Behavior of Polylactide/Graphene Composites. Ind. Eng. Chem. Res. 2013, 52, 6731-6739. [CrossRef]

7. Lim, J.W.; Lee, D.G. Carbon fiber/polyethylene bipolar plate-carbon felt electrode assembly for vanadium redox flow batteries (VRFB). J. Compos. Struct. 2015, 134, 483-492. [CrossRef]

8. Daugherty, M.C.; Siyong, G.; Aaron, D.S. Graphene quantum dot-decorated carbon electrodes for energy storage in vanadium redox flow batteries. J. Nanoscale 2020, 12, 7834-7842. [CrossRef]

9. Zhou, W.B. Preparation and thermodynamic analysis of the porous $\mathrm{ZrO}_{2} /\left(\mathrm{ZrO}_{2}+\mathrm{Ni}\right)$ functionally graded bolted joint. J. Compos. Part B Eng. 2015, 82, 13-22. [CrossRef] 
10. Bian, Z.G.; Ying, J.; Chen, W.Q.; Ding, H.J. Bending and free vibration analysis of a smart functionally gradedplate. J. Struct. Eng. Mech. 2006, 23, 97-113. [CrossRef]

11. Fakhari, V.; Ohadi, A.; Yousefian, P. Nonlinear free and forced vibration behavior of functionally graded plate with piezoelectric layers in thermal environment. J. Compos. Struct. 2011, 93, 2310-2321. [CrossRef]

12. Fakhari, V.; Ohadi, A. Nonlinear vibration control of functionally graded plate with piezoelectric layers in thermal environment. J. Vib. Control 2011, 17, 449-469. [CrossRef]

13. Jandaghian, A.A.; Rahmani, O. Size-dependent free vibration analysis of functionally graded piezoelectric plate subjected to thermoelectro-mechanical loading. J. Intell. Mater. Syst. Struct. 2017, 28, 3039-3053. [CrossRef]

14. Li, J.Q.; Xue, Y.; Li, F.M.; Narita, Y. Active vibration control of functionally graded piezoelectric material plate. J. Compos. Struct. 2019, 207, 509-518. [CrossRef]

15. Farzam, A.; Hassani, B. Size-dependent analysis of FG microplates with temperature-dependent material properties using modified strain gradient theory and isogeometric approach. J. Compos. Struct. 2019, 161, 150-168. [CrossRef]

16. Karamanli, A.; Aydogdu, M.; Vo, T.P. A comprehensive study on the size-dependent analysis of strain gradient multi-directional functionally graded microplates via finite element model. J. Aerosp. Sci. Technol. 2021, 111, 106550. [CrossRef]

17. Mao, K. Free Vibration Analysis of Functionally Gradient Sandwich Composite Plate Embedded SMA Wires in Surface Layer. Appl. Sci. 2020, 10, 3921.

18. Cho, J.R. Hierarchic models for the free vibration analysis of functionally gradient plates. Int. J. Mech. Mater. Des. 2021, 17, 489-501. [CrossRef]

19. Mehrabadi, S.J.; Kargarnovin, M.H.; Najafizadeh, M.M. Free vibration analysis of functionally Graded coupled circular plate with piezoelectric layer. J. Mech. Sci. Technol. 2009, 23, 2008-2021. [CrossRef]

20. Yao, L. Analysis of the Vibration Behaviors of Rotating Composite Nano-Annular Plates Based on Nonlocal Theory and Different Plate Theories. J. Appl. Sci. 2021, 12, 230.

21. Mlab, C.; Cgs, C.; Rya, B. A novel shear deformation theory for static analysis of functionally graded plates-ScienceDirect. J. Compos. Struct. 2020, 250, 12559.

22. Zenkour, A.M.; Hafed, Z.S. Bending analysis of functionally graded piezoelectric plates via quasi-3D trigonometric theory. $J$. Mech. Adv. Mater. Struc. 2019, 18, 1-12. [CrossRef]

23. Amini, M.H.; Soleimani, M.; Rastgoo, A. Three-dimensional free vibration analysis of functionally graded material plates resting on an elastic foundation. J. Smart Mater. Struct. 2009, 18, 085015. [CrossRef]

24. Musa, A.; Alshugaa, M.A.; Algahtani, H.J. EnergyBased Solution for Bending Analysis of Thin Plates on Nonhomogeneous Elastic Foundation. Arab. J. Sci Eng. 2020, 45, 3817-3827. [CrossRef]

25. Pham, P. Free vibration of cracked FGM plates with variable thickness resting on elastic foundations. Thin-Walled Struct. 2021, $161,107425$.

26. Merazka, B.; Bouhadra, A.; Menasria, A. Hygro-thermo-mechanical bending response of FG plates resting on elastic foundations. Steel Compos. Struct. 2021, 39, 631-643.

27. Tounsi, A.; Al-Dulaijan, S.U.; Al-Osta, M. A four variable trigonometric integral plate theory for hygro-thermo-mechanical bending analysis of AFG ceramic-metal plates resting on a two-parameter elastic foundation. Steel Compos. Struct. 2020, 34, 511-524.

28. Ebrahimi, F.; Barati, M.R.A. Nonlocal Higher Order Shear Deformation Beam Theory for Vibration Analysis of Size-Dependent Functionally Graded Nanobeams. Arab. J. Sci. Eng. 2016, 41, 1679-1690. [CrossRef]

29. Shu, C. Differential Quadrature and Its Application in Engineering; Springer: London, UK, 2000.

30. Ming, S.; Zhi, Y. Thermoelectromechanical Properties of Piezoelectric Nanoplates with Flexoelectricity. J. Mech. Phys. Solids 2020, $41,444-454$. 